\title{
Influence of Quality of Sleep on the Nocturnal Decline in Blood Pressure During Ambulatory Blood Pressure Monitoring
}

\author{
Alexandre Alessi, Cristiane Rodrigues Alessi, Edson Rogério Piana, Márcia Assis, Luciano Rodrigo Oliveira, \\ Cláudio L. Pereira da Cunha \\ Curitiba, PR - Brazil
}

Objective - To assess the influence of the quality of sleep on the nocturnal physiological drop in blood pressure during ambulatory blood pressure monitoring.

Methods - We consecutively assessed ambulatory blood pressure monitoring, the degree of tolerance for the examination, and the quality of sleep in 168 patients with hypertension or with the suspected "white-coat" effect. Blood pressurefall during sleep associated with a specific questionnaire and an analogical visual scale of tolerance for ambulatory blood pressure monitoring were used to assess usual sleep and sleep on the day of examination. Two specialists in sleep disturbances classified the patients into 2 groups: those with normal sleep and those with abnormal sleep.

Results - Fifty-nine (35\%) patients comprised the abnormal sleep group. Findings regarding the quality of sleep on the day of ambulatory blood pressure monitoring as compared with those regarding the quality of sleep on a usual day were different and were as follows, respectively: total duration of sleep $(-12.4 \pm 4.7$ versus $-42.2 \pm 14.9$ minutes, $P=0.02)$, latency of sleep $(0.4 \pm 2.7$ versus $17 \pm 5.1$ minutes, $P<0.001)$, number of awakenings $(0.1 \pm 0.1$ versus $1.35 \pm 0.3$ times, $P<0.001)$, and tolerance for ambulatory blood pressure monitoring $(8 \pm 0.2$ versus $6.7 \pm 0.35, P=0.035)$. An abnormal drop in blood pressure during sleep occurred in 20 (18\%) patients in the normal sleep group and in 14 (24\%) patients in the abnormal sleep group, $P=0.53$.

Conclusion -Ambulatory blood pressure monitoring causes sleep disturbances in some patients, and a positive association between quality of sleep and tolerance for the examination was observed.

Keywords: hypertension, ambulatory blood pressure monitoring, sleep disturbances

Universidade Federal do Paraná

Mailing address: Alexandre Alessi - Rua Padre Agostinho, 1923/1701 - 80710-000 Curitiba, PR, Brazil - E-mail: acalessi@terra.com.br

English version by Stela Maris C. e Gandour
Cessation of vigil consciousness, with the concomitant reduction in the response to the environment, leads to multiple changes in the circadian rhythm of vital functions, such as the sleep-wake cycle of blood pressure ${ }^{1}$. During sleep, a mean physiological $10 \%$ reduction in blood pressure is known to occur, which depends on arterial vasodilation ${ }^{2}$. This fall in blood pressure occurring during sleep is the result of a reduction in physical, mental, and sympathetic activities ${ }^{3}$.

Since the beginning of blood pressure measurement with the palpation technique, the reduction in blood pressure levels during sleep as compared with the levels during the period of wakefulness has attracted the attention of researchers ${ }^{4}$. In 1969, Bevan et $\mathrm{al}^{5}$ were pioneers in the experimental assessment of blood pressure levels in sleeping patients, through intraarterial measurement. In 1975, measurement of arterial blood pressure during different activities and during sleep began to be used in clinical practice ${ }^{6,7}$. The importance of detection of blood pressure variability over 24 hours, specifically during the sleep-wakefulness period, has increased after the miniaturization of the measuring equipment and recognition of the clinical importance of hemodynamic alterations during sleep. At the end of the 1980s, the terms "dipper" and "nondipper" began to be used to classify individuals with normal and abnormal drop in blood pressure during sleep, respectively ${ }^{8}$. Currently, the most accessible way of assessing the fall in blood pressure during sleep is through 24-hour ambulatory blood pressure monitoring 9,10.

The inadequate fall in blood pressure during sleep detected on ambulatory blood pressure monitoring correlates with the presence of lesions in target organs ${ }^{11-18}$. This shows that this parameter is superior to the occasional measurements of arterial blood pressure in the prognostic analysis of hypertensive patients ${ }^{18}$. However, ambulatory blood pressure monitoring, through sonorous, tactile, and compressive stimuli, has been reported to cause a disarray in the usual architecture of sleep, leading to an increase in awakenings, to difficulty in initiating or maintaining normal sleep, or even to excessive diurnal sleepiness. Because of 
these discomforts, caution in using the blood pressure parameters obtained in ambulatory blood pressure monitoring during the nocturnal period has been recommended ${ }^{19}$.

The objective of this study was to analyze how ambulatory blood pressure monitoring, which is an auxiliary method in the diagnostic, prognostic, and therapeutic evaluation of hypertension, influences the quality of sleep and the pattern of blood pressure drop during sleep.

\section{Methods}

We consecutively studied 168 patients with hypertension or suspicion of the "white-coat" effect, who were referred for ambulatory blood pressure monitoring in a general university-affiliated hospital from January 1997 to July 1998. All patients underwent the first examination. The cases with poor technical quality in ambulatory blood pressure monitoring (duration of examination less than 21 hours, fewer than 70 valid readings, reading success lower than $80 \%$, and no-reading interval(s) longer than 2 hours) were excluded from the study. Patients referred with the diagnosis of secondary arterial hypertension, and individuals using sedatives or hypnotic drugs on the night of the examination were also excluded. Ambulatory blood pressure monitoring was performed with the SpaceLabs 90207 monitor, through the sphygmo-oscillometric form of blood pressure measurement, with indirect, programmed, and intermittent measurements. The monitors were placed and withdrawn in the morning, on a day with usual activities, according to the recommendations of the Brazilian Consensus of Ambulatory Blood Pressure Monitoring ${ }^{20}$. The readings were programmed at 15 -minute intervals, from 6 AM to $10 \mathrm{PM}$, and at every 20 minutes, from $10 \mathrm{PM}$ to $6 \mathrm{AM}$. A sonorous warning prior to cuff inflation remained on during the measurements from 6 AM to $10 \mathrm{PM}$. The patients filled out a diary that provided identification of their activities, symptoms, medication used, and sleep and awakening times.

Determination of the wakefulness and sleep periods was time-dependent on short periods as follows: wakefulness period ranging from $10 \mathrm{AM}$ to $10 \mathrm{PM}$, and sleep period from $12 \mathrm{PM}$ to $6 \mathrm{AM}^{21,22}$. Drop in blood pressure during sleep was defined as the reduction in blood pressure levels during sleep as compared with the levels in the period of wakefulness ${ }^{23}$. Individuals with an adequate drop in blood pressure during sleep had a simultaneous drop in systolic and diastolic blood pressure levels $\leq 10 \%$; individuals with an inadequate fall in blood pressure during sleep had a nocturnal drop in systolic or diastolic blood pressure levels, or both, $<10 \%{ }^{24}$.

Quality of sleep was evaluated through the analysis of a questionnaire previously used in population investigations ${ }^{25-30}$. The degree of tolerance for the examination was measured through a linear analogical visual scale graded from 0 to $10^{31}$. The questionnaire about quality of sleep applied right after withdrawal of the monitor provided comparative information between the usual sleep and sleep on the day of ambulatory blood pressure monitoring. We collected data about latency of sleep (period of time between the intention to sleep and the effective beginning of sleep), time spent in bed (period of time between going to bed to sleep and getting up after waking up), duration of sleep (period of effective sleep), and presence and number of nocturnal awakenings. In regard to tolerance, ambulatory blood pressure monitoring was classified as follows: tolerable ( $\geq 8.6)$, less tolerable (from 6.5 to 8.5 ), and intolerable $(<6.5)^{31}$. Data referring to quality of sleep were analyzed according to the criteria of the Epworth sleepiness scale ${ }^{30}$ and the Stanford sleepiness scale ${ }^{29}$ by 2 neurologists specially trained in sleep disturbances. They classified separately and without knowing the ambulatory blood pressure monitoring parameters those individuals who had a type of sleep considered adequate or inadequate during ambulatory blood pressure monitoring. The cases upon which they disagreed were assessed by a third evaluator.

Nominal categorical variables were expressed by their respective proportions. The estimate of the degree of association was performed using the contingence table (chisquare). Continuous variables were expressed by mean \pm standard deviation. The normal distribution of data was evaluated using the Kolmogorov-Smirnov test, prior to the application of the parametric (Student $t$ test) or nonparametric (Wilcoxon rank-sum test) test. The minimum significance level adopted was 5\%.

\section{Results}

The sleep evaluators agreed on the questionnaire analyses of 155 (92.7\%) patients. The 13 remaining patients were analyzed by a third evaluator. On final consensus, 109 (64.9\%) patients had a normal sleep quality, and 59 (35.1\%) patients had an abnormal sleep quality on the day of ambulatory blood pressure monitoring.

Table I shows the major demographic characteristics and blood pressure levels obtained with ambulatory blood pressure monitoring according to sleep quality during the examination. The sample showed no significant differences in the demographic data, in the major risk factors for coronary artery disease, and in blood pressure levels obtained on ambulatory blood pressure monitoring in 24 hours.

Figure 1 shows the values calculated for the fall of systolic $(12.27 \pm 1.42$ versus $10.54 \pm 1.37, \mathrm{P}=0.10)$ and diastolic ( $16.86 \pm 1.53$ versus $15.44 \pm 1.59, \mathrm{P}=0.91)$ blood pressure levels during sleep in the groups with normal and abnormal sleep, respectively, and no significant difference could be seen between them. Typical graphic representations of different patterns of blood pressure drop during sleep are shown in figures 2 and 3 .

The number of patients with inadequate blood pressure drop during sleep was similar in the 2 study groups. Twenty $(18.3 \%)$ patients with inadequate blood pressure drop during sleep were found in the normal sleep group, and 14 (23.7\%) patients with inadequate blood pressure drop during sleep were found in the abnormal sleep group $(\mathrm{P}=0.53)$.

Information obtained using the sleep quality question- 


\begin{tabular}{|c|c|c|c|}
\hline & $\begin{array}{l}\text { Normal sleep } \\
\quad(\mathrm{n}=109)\end{array}$ & $\begin{array}{l}\text { Abnormal sleep } \\
\qquad(\mathrm{n}=59)\end{array}$ & $\mathrm{p}$ \\
\hline Sex (male/female) & $52 / 57$ & $26 / 33$ & 0.53 \\
\hline Age (years) & $46.89 \pm 12.61$ & $49.91 \pm 12.40$ & 0.13 \\
\hline Age above 60 years $(\%)$ & 24.5 & 19.4 & 0.59 \\
\hline Diabetes $(\%)$ & 21.13 & 25.42 & 0.069 \\
\hline Smoking $(\%)$ & 30.02 & 28.81 & 0.063 \\
\hline Obesity - BMI $\left(\mathrm{kg} / \mathrm{m}^{2}\right) *$ & $25.29 \pm 3.65$ & $25.20 \pm 3.51$ & 0.81 \\
\hline \multicolumn{4}{|l|}{ Indication for examination: } \\
\hline $\begin{array}{l}\text { - therapeutic control of hypertension/ } \\
\text { - assessment of the "white-coat" effect }\end{array}$ & $58 / 48$ & $29 / 33$ & 0.69 \\
\hline \multicolumn{4}{|l|}{ 24-hour blood pressure $(\mathrm{mm} \mathrm{Hg})$} \\
\hline- Systolic & $134.12 \pm 13.25$ & $135.34 \pm 14.27$ & 0.58 \\
\hline - Diastolic & $84.50 \pm 10.62$ & $84.68 \pm 9.48$ & 0.91 \\
\hline \multicolumn{4}{|l|}{ Awake blood pressure $(\mathrm{mm} \mathrm{Hg})$} \\
\hline - Systolic & $139.02 \pm 13.71$ & $137.94 \pm 14.65$ & 0.63 \\
\hline - Diastolic & $88.52 \pm 9.86$ & $87.87 \pm 9.86$ & 0.71 \\
\hline \multicolumn{4}{|l|}{ Asleep blood pressure $(\mathrm{mm} \mathrm{Hg})$} \\
\hline- Systolic & $121.44 \pm 13.54$ & $123.78 \pm 15.30$ & 0.30 \\
\hline - Diastolic & $73.03 \pm 9.16$ & $74.61 \pm 10.45$ & 0.32 \\
\hline
\end{tabular}

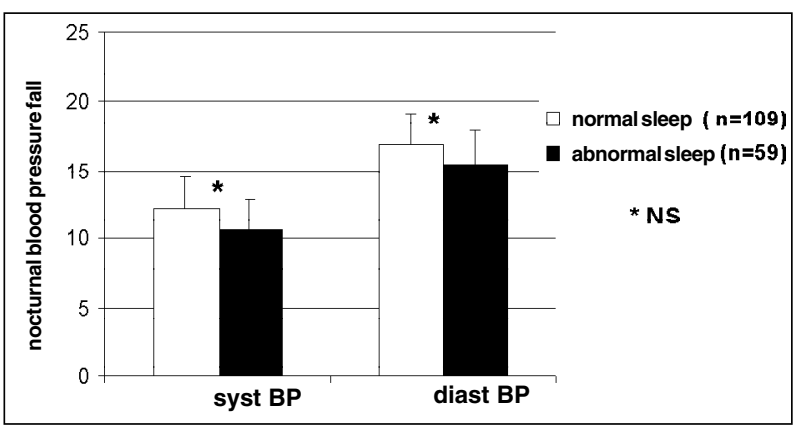

Fig. 1 - Systolic and diastolic blood pressure fall during sleep. Nocturnal systolic and diastolic blood pressure fall in the groups with different qualities of sleep. No difference between the groups was observed: syst $\mathrm{BP}$ (systolic blood pressure), $\mathrm{P}=0.10$; diast $\mathrm{BP}$ (diastolic blood pressure), $\mathrm{P}=0.91$.

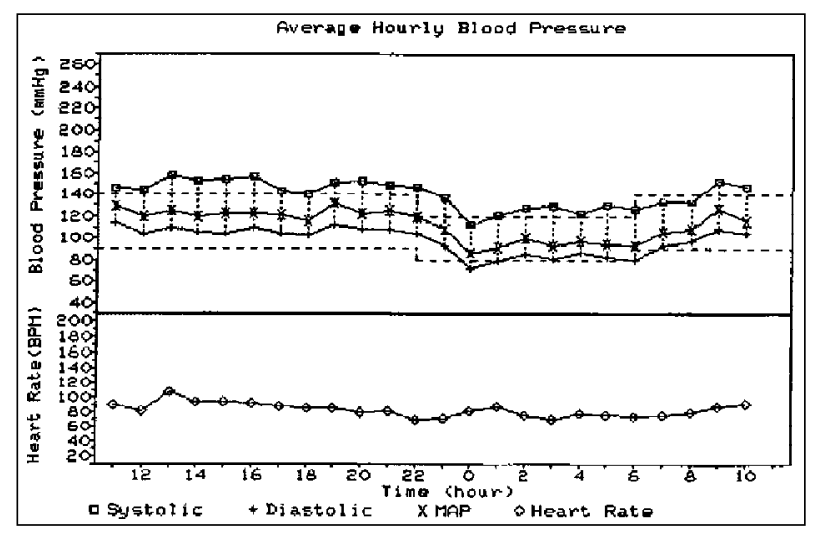

Fig. 2 - Adequate blood pressure fall during sleep.

Systolic and diastolic blood pressure fall during sleep $>10 \%$ of awake blood pressure levels.

naire and the analogical visual scale of tolerance for ambulatory blood pressure monitoring is summarized in table II. We observed that the total time spent in bed was similar for

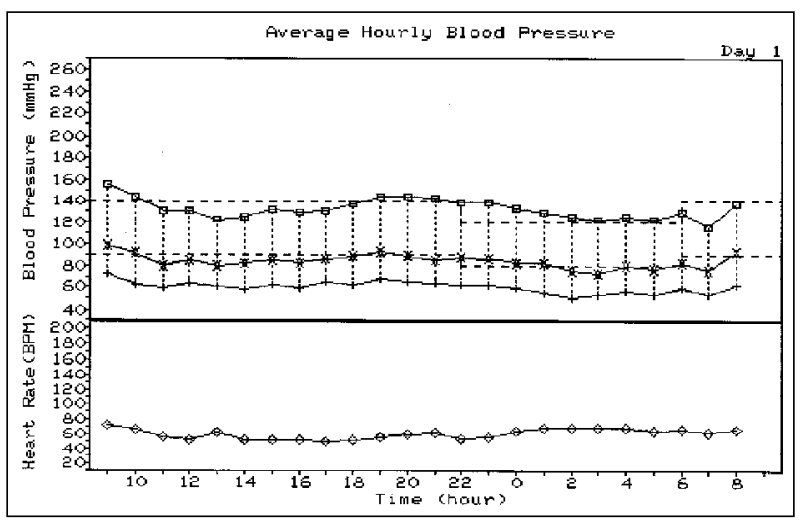

Fig. 3 - Inadequate blood pressure fall during sleep.

Systolic and diastolic blood pressure fall during sleep $<10 \%$ of awake blood pressure levels.

both groups, but the other parameters collected in the sleep questionnaire showed the degree of interference and discomfort created on the night of the examination. The degree of tolerance for ambulatory blood pressure monitoring had a positive association with the quality of sleep during examination (fig. 4), evidencing the importance of adaptation to examination during sleep in the global acceptance of this diagnostic test.

\section{Discussion}

The population of the present study was homogeneous in gender and age, reducing the influence of the poor quality of sleep, mainly in the female $\operatorname{sex}^{32}$ and elderly patients ${ }^{27}$. In the elderly patients, the nocturnal parameters of ambulatory blood pressure monitoring should be cautiously analyzed ${ }^{11}$; an elevated prevalence of insomnia exists in this age group ${ }^{33}$.

When performing ambulatory blood pressure mo- 


\begin{tabular}{|c|c|c|c|}
\hline \multicolumn{4}{|c|}{$\begin{array}{l}\text { Table II - Data obtained by the analysis of the quality of sleep } \\
\text { questionnaires and the degree of tolerance for examination }\end{array}$} \\
\hline & $\begin{array}{l}\text { Normal sleep } \\
(\mathrm{n}=109)\end{array}$ & $\begin{array}{l}\text { Abnormal sleep } \\
(\mathrm{n}=59)\end{array}$ & $\mathrm{p}$ \\
\hline Total time spent in bed (minutes & s) * $6.83 \pm 4.02$ & $-15.17 \pm 8.03$ & 0.26 \\
\hline Total sleep duration (minutes) * & $-12.44 \pm 4.66$ & $-42.20 \pm 14.92$ & 0.02 \\
\hline Sleep latency (minutes) $*$ & $0.36 \pm 2.7$ & $17 \pm 5.06$ & $<0.001$ \\
\hline Nocturnal awakenings $*$ & $0.1 \pm 0.1$ & $1.3 \pm 0.2$ & $<0.001$ \\
\hline Tolerance degree for ABPM $* *$ & $7.96 \pm 0.23$ & $6.67 \pm 0.35$ & 0.035 \\
\hline \multicolumn{4}{|c|}{$\begin{array}{l}\text { ABPM - ambulatory blood pressure monitoring; } * \text { means the difference } \\
\text { between the absolute values of sleep during ABPM and usual sleep of the } \\
\text { patients; } * * \text { according to the visual analogical scale and tolerance for ABPM }\end{array}$} \\
\hline
\end{tabular}

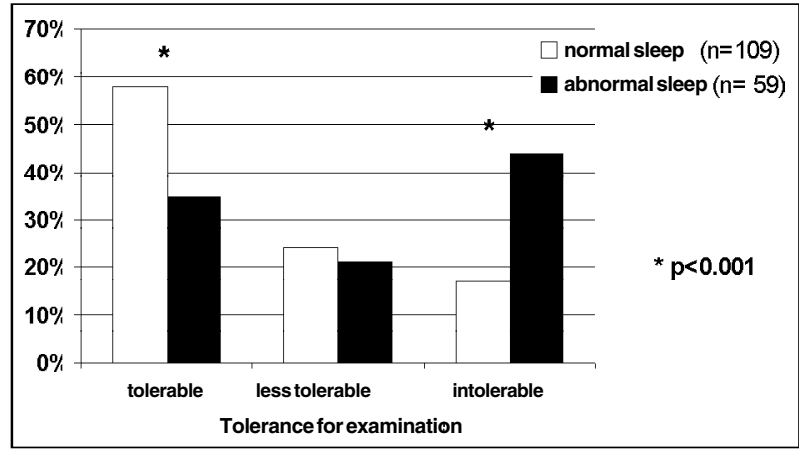

Fig. 4-Degree of tolerance for ABPM according to quality of sleep.

nitoring more than once, some patients get used to the procedure and report a lower intolerance to the examination. For others, the fact of knowing the discomforts generated by a prior examination may increase the intolerance threshold and sleep disturbances ${ }^{33}$. As we decided not to condition patients to ambulatory blood pressure monitoring, we excluded those who had undergone a prior examination and avoided repeating the examination in the patients included in the study. This exclusion criterion may have limited the interpretation of data because of the low reproducibility of data of ambulatory blood pressure monitoring in the analysis of blood pressure drop during sleep. According to some authors, examinations repeated in different populations showed that $20 \%$ to $40 \%$ of the individuals considered nondippers on a first examination may behave as dippers on a $2^{\text {nd }}$ monitoring and vice-versa ${ }^{34,35}$. However, recent studies specifically directed to reproducibility of the presentation of blood pressure drop during sleep showed no statistical differences after 4 examinations of ambulatory blood pressure monitoring in the same patient, performed on the same weekday at 30 -day intervals ${ }^{36}$. The possible factors involved in the reproducibility of ambulatory blood pressure monitoring could be the following: different daily activities on different days of examination, a reduction in accuracy due to very high levels of blood pressure, differences in the quality of sleep, and limitation of the examination in conditions of ambulatory measurements ${ }^{37}$.

Noninclusion of patients with diagnosed or suspected secondary hypertension according to medical requisitions
Quality of sleep on the nocturnal decline in blood pressure

aimed to exclude patients with previous alterations in blood pressure drop during sleep, which do not depend on the quality of sleep ${ }^{23}$. Reports that these patients may not have an adequate nocturnal blood pressure drop exist ${ }^{38}$. The use of substances that interfere with normal sleep architecture, such as anxiolytics or sleep inductors, was also considered in the exclusion criteria.

Programming the number of blood pressure measurements chosen is in accordance with the criteria recommended in the literature and consists of the following: at least 3 readings per hour during the day and 2 readings per hour during the night ${ }^{20,39}$. A lower frequency of measurements during sleep may reduce the discomfort generated by multiple sonorous, tactile, and compressive stimuli, caused by cuff inflation ${ }^{19}$. Pressure means were defined in 24-hour periods, in periods of wakefulness and sleep ${ }^{40}$. The terms "day and night" were not used because they do not correspond to the levels of physical activity and rest that are characteristic of wakefulness and sleep, respectively.

No consensus exists for the definition of blood pressure during wakefulness and during sleep so far, and at least 10 different methods have been used to analyze ambulatory blood pressure monitoring ${ }^{41}$. The techniques used may be time-independent or time-dependent (short and long periods $)^{41}$. The use of predetermined short periods allows the exclusion of the transitional periods in which blood pressure rapidly varies from the analysis of the wakefulness profile. Arguments against this technique exist, suggesting that not all information about blood pressure levels is available in the analysis of blood pressure drop during short periods of time; however, in the 24-hour analysis, all values collected are analyzed.

Blood pressure drop during sleep is calculated using the percent ratio of the pressure levels between the periods of wakefulness and sleep and not using the pressure difference between these periods. Therefore, it excludes the influence of the absolute value of blood pressure and the overestimation of the number of patients with adequate blood pressure drop ${ }^{20,23}$. Inadequate blood pressure drop during sleep was defined as systolic and diastolic blood pressure fall lower than $10 \%$, together or isolated. This definition has raised controversies. A more strict definition of inadequate blood pressure fall during sleep, which requires that both blood pressure levels have inadequate nocturnal falls, is closer to the actual prevalence of the patients considered nondippers ${ }^{42}$. In regard to lesions in target organs, the worse prognosis in hypertensive patients with inadequate blood pressure drop during sleep is associated with left ventricular hypertrophy ${ }^{12}$, cerebrovascular damage ${ }^{14,15}$, and microalbuminuria ${ }^{17}$. These patients are the nondippers who have a higher probability of complications associated with hypertension ${ }^{24}$. Until the present time, the prognostic significance of inadequate blood pressure drop during sleep in normotensive individuals has not yet been defined.

Polysomnography is the gold standard for assessing sleep disturbances, but requires an adequate environment 
for its performance and has an elevated operational cost ${ }^{43}$. Several studies have been directed at assessing quality of sleep in the general population using questionnaires, mainly the epidemiological kind, in which the number of participants is high ${ }^{27,28}$. The epidemiology of acute or transitory sleep disturbances is not well known, because of methodological limitations in this research area, such as the use of small or nonrandomized samples in several studies. Approximately $30 \%$ to $35 \%$ of adults report difficulties in sleeping at some point in their lives, and $10 \%$ to $15 \%$ report chronic or severe sleep problems. Almost everybody has already experienced an occasional night of little sleep either caused by transitory stress or by recent events with greater stimuli or annoyances ${ }^{44}$.

In this study, we chose to use a specific questionnaire about quality of sleep, which comprised subjective items that were easily collected and necessary for the most adequate classification. We used the classifying items of the Stanford and Epworth sleepiness scales, which are most frequently used for this purpose ${ }^{29,30}$. This methodology does not transform the patient's night into an unusual situation and is performed in the household of any patient taking part in the research and undergoing ambulatory blood pressure monitoring. These questionnaires are simple, short, and may provide a valid measurement of quality of sleep in adults ${ }^{45,46}$. The subjective analysis of sleep does not replace the gold-standard examination, which is polysomnography ${ }^{43}$, but provides a fair estimate of sleep quality at an accessible cost and with no change in sleep environment during conventional ambulatory blood pressure monitoring. A high concordance in the classification of the patients in regard to sleep quality was found among the evaluators, which validates, in this study, the applied questionnaire as an instrument of data collection and classification. The conflicting items between the usual sleep condition and that on the day of ambulatory blood pressure monitoring allowed the distinction of patients who might have chronic sleep disturbances from those with an acute disturbance of sleep fragmentation caused only on the day of examination.

Our data on sleep latency, time spent in bed, total duration of sleep, and presence of naps are in accordance with those found in the literature ${ }^{19,47,48}$. Reports in the literature show that, during polysomnography and ambulatory blood pressure monitoring, an increase in the frequency ${ }^{19,49}$ and duration of awakenings ${ }^{48}$ occurs because of the discomfort generated by excessive cuff inflations.

According to some researchers, the major disadvantage of ambulatory blood pressure monitoring is sleep disturbance, which causes artifacts in the nocturnal parameters, and, consequently, makes the precise classification of blood pressure fall during sleep unfeasible ${ }^{50,51}$. From the practical point of view, these considerations raised some doubts and questions about the actual influence of adequate and inadequate sleep on the presentation of blood pressure fall during sleep and the reliability of this parameter in patients who do not sleep well or who do not tolerate ambulatory blood pressure monitoring.

The participation of neurologists who specialized in sleep disturbances in the elaboration of the questionnaire and the analysis of data collected, when considering the usual characteristics of sleep, is the great strength of this study. This is the first report in the Brazilian literature about a combined analysis of sleep quality assessed on a specific questionnaire, and its influence on the pattern of blood pressure drop during sleep obtained using ambulatory blood pressure monitoring.

A positive association was found between the degree of tolerance for the examination and sleep quality; the most tolerant patients more frequently had adequate sleep. This correlation between tolerance for the examination and the subjective quality of sleep on the day of ambulatory blood pressure monitoring is also reported in a pioneering way in this study. Sleep disturbance is believed to be the major adverse effect of the examination, and it results from the poor tolerance for the examination and vice-versa.

In conclusion, this study shows that tolerance for ambulatory blood pressure monitoring is closely related to quality of sleep, and that an association between the subjective quality of sleep and the presentation of blood pressure drop during sleep does not occur. This information supports a safer interpretation of data referring to blood pressure drop during sleep, independent of the quality of sleep reported by the patient, when the methodology applied during ambulatory blood pressure monitoring is in accordance with the guidelines of the current consensus statement.

\section{References}

1. Reimão R. Fisiologia do sono. Sono um estudo abrangente. São Paulo: Atheneu, 1996.

2. Mancia G, Zanchetti A. Cardiovascular regulation during sleep. Physiology during sleep. New York: Academic Press, 1980: 1-16.

3. Littler WA. Sleep and blood pressure: further observations. Am Heart J 1979; 97: $35-7$.

4. Hill L. On rest, sleep and work and the concomitant changes in the circulation of blood. Lancet 1898; i: 282-5.

5. Bevan AT, Honour AJ, Stott FH. Direct arterial pressure recording in unrestricted man. Br Heart J 1969; 31: 387-8.

6. Littler WA, Honour AJ, Pugsley DJ, Sleight P. Continuous recording of direct arterial pressure in unrestricted patients: its role in the diagnosis and management of high blood pressure. Circulation 1975; 51 : 1101-06.

7. Littler WA, West MJ, Honour AJ, Sleight $P$. The variability of arterial pressure. Am Heart J 1978; 95: 180-6.

8. O'Brien E, Sheridan J, O'Malley K. Dippers and non-dippers. Lancet 1988; 2: 397.

9. Pickering TG. The influence of daily activity on ambulatory blood pressure. Am Heart J 1988; 116: 1141-5.

10. Pickering TG, James GD. Ambulatory blood pressure and prognosis. J Hypertens Suppl 1994; 12: S29-S33. 
11. Middeke M. Effect of nocturnal blood pressure measurement on sleep and blood pressure during sleep. Z Kardiol 1996; 85(suppl 3): 99-105.

12. Verdecchia P, Schillaci G, Guerrieri M, et al. Circadian blood pressure changes and left ventricular hypertrophy in essential hypertension. Circulation 1990; 81: 528-36.

13. Staessen J, Fagard R, Lijnen P, Thijs L, van Hoof R, Amery A. Ambulatory blood pressure monitoring in clinical trials. J Hypertens Suppl 1991; 9: S13-S19.

14. Shimada K, Kawamoto A, Matsubayashi K, Nishinaga M, Kimura S, Ozawa T Diurnal blood pressure variations and silent cerebrovascular damage in elderly patients with hypertension. J Hypertens 1992; 10: 875-8.

15. Kario K, Matsuo T, Kobayashi H, Imiya M, Matsuo M, Shimada K. Nocturnal fall of blood pressure and silent cerebrovascular damage in elderly hypertensive patients: advanced silent cerebrovascular damage in extreme dippers. Hypertension 1996; 27: 130-5.

16. Verdecchia P, Porcellati C, Schillaci G, et al. Ambulatory blood pressure: an independent predictor of prognosis in essential hypertension [published erratum appears in Hypertension 1995; 25: 462]. Hypertension 1994; 24: 793-801.

17. Bianchi S, Bigazzi R, Baldari G, Sgherri G, Campese VM. Diurnal variations of blood pressure and microalbuminuria in essential hypertension. Am J Hypertens 1994; 7: 23-9.

18. Mancia G, Zanchetti A, Agabiti-Rosei E, et al. Ambulatory blood pressure is superior to clinic blood pressure in predicting treatment-induced regression of left ventricular hypertrophy. SAMPLE Study Group. Study on Ambulatory Monitoring of Blood Pressure and Lisinopril Evaluation [published erratum appears in Circulation 1997 Aug 5; 96: 1065]. Circulation 1997; 95: 1464-70.

19. Schwan A, Eriksson G. Effect on sleep-but not on blood pressure-of nocturnal noninvasive blood pressure monitoring. J Hypertens 1992; 10: 189-94.

20. Amodeo C, Giorgi DM, Mion Jr D, et al. II Brazilian Consensus of Ambulatory Blood Pressure Monitoring. Arq Bras Cardiol 1997; 69: 359-67.

21. Staessen J, Bulpitt CJ, Fagard R, et al. Reference values for the ambulatory blood pressure and the blood pressure measured at home: a population study. J Hum Hypertens 1991; 5: 355-61.

22. Fagard R, Brguljan J, Thijs L, Staessen J. Prediction of the actual awake and asleep blood pressures by various methods of $24 \mathrm{~h}$ pressure analysis. J Hypertens 1996; 14: 557-63

23. Staessen JA, Bieniaszewski L, O'Brien E, et al. Nocturnal blood pressure fall on ambulatory monitoring in a large international database. The "Ad Hoc" Working Group. Hypertension 1997; 29(1 Pt 1): 30-9.

24. Pickering TG. The clinical significance of diurnal blood pressure variations: dippers and nondippers. Circulation 1990; 81: 700-2.

25. Bursztyn M, Mekler J, Wachtel N, Ben Ishay D. Siesta and ambulatory blood pressure monitoring: comparability of the afternoon nap and night sleep. Am J Hypertens 1994; 7: 217-21.

26. Ishihara Y, Sakai H, Nukariya N, et al. Development of quality of life (QOL) questionnaire for use of lung cancer patients in palliative therapy-study of validity and reliability no. 2, the effects of chemotherapeutics in QOL. Gan To Kagaku Ryoho 1995; 22: 1087-93.

27. Middelkoop HA, Smilde-van den Doel DA, Neven AK, Kamphuisen HA, Springer CP. Subjective sleep characteristics of 1,485 males and females aged 5093: effects of sex and age, and factors related to self-evaluated quality of sleep. $\mathbf{J}$ Gerontol A Biol Sci Med Sci 1996; 51: M108-M15.

28. Jaffe MP, Smolensky MH, Wun CC. Sleep quality and physical and social wellbeing in North American petrochemical shift workers. South Med J 1996; 89: 305-12

29. Hoddes E, Zarcone V, Smythe H, Phillips R, Dement WC. Quantification of sleepiness: a new approach. Psychophysiology 1973; 10: 431-6.

30. Johns MW. A new method for measuring daytime sleepiness: the Epworth sleepiness scale. Sleep 1991; 14: 540-5.

31. Beltman FW, Heesen WF, Smit AJ, May JF, Lie KI, Meyboom-de Jong B.
Acceptance and side effects of ambulatory blood pressure monitoring: evaluation of a new technology. J Hum Hypertens 1996; 10(suppl 3): S39-S42.

32. Ohayon M. Epidemiological study on insomnia in the general population. Sleep 1996; 19(3 suppl): S7-15.

33. Karacan I, Thorby JI, Willians RL. Sleep disturbance: a community survey. In Guilleminault C, Lugaresi E. Sleep/Wake disorders: natural history, epidemiology and long-term evolution. New York: Raven Press 1983: 37-59.

34. Mochizuki Y, Okutani M, Donfeng Y, et al. Limited reproducibility of circadian variation in blood pressure dippers and nondippers. Am J Hypertens 1998; 11(4 Pt 1): 403-9.

35. Peixoto AJ, Santos SF, Mendes RB, et al. Reproducibility of ambulatory blood pressure monitoring in hemodialysis patients. Am J Kidney Dis 2000; 36: 983-90.

36. Zakopoulos NA, Nanas SN, Lekakis JP, et al. Reproducibility of ambulatory blood pressure measurements in essential hypertension. Blood Press Monit 2001; 6: 41-5.

37. Van der Steen MS, Lenders JW, Graafsma SJ, den Arend J, Thien T. Reproducibility of ambulatory blood pressure monitoring in daily practice. J Hum Hypertens 1999; 13: 303-8

38. Spritzer N. MAPA como método diagnóstico. In: Mion Jr D, Nobre F, Oigman W, editors. MAPA: Monitorização Ambulatorial da Pressão Arterial. São Paulo: Atheneu, 1995: 49-68.

39. Lima Jr E. Protocolos para realização da MAPA. In: Mion Jr D, Nobre F, Oigman W, editors. MAPA: monitorização ambulatorial da pressão arterial. São Paulo: Atheneu, 1995: 115-20.

40. Pickering TG. A review of national guidelines on the clinical use of ambulatory blood pressure monitoring. Blood Press Monit 1996; 1: 151-6.

41. O’Brien O, Pickering TG, van Montfrans GA, Di Rienzo M, Fagard R. Blood Pressure Monitoring. Task force I: Methodological aspects. Blood Press Monit 1999; 4: 279-93

42. Palatini P, Penzo M, Racioppa A, et al. Clinical relevance of nighttime blood pressure and of daytime blood pressure variability. Arch Intern Med 1992; 152: 1855-60.

43. Carkadon MA, Rechtschaffen A. Monitoring and staging human sleep. In Krieger MH, Roth T, Dement WC, editors. Principles and Pratice of Sleep Medicine. Philadelphia: WB Saunders, 1989: 665-83.

44. Klink ME, Quan SF, Kaltenborn WT, Lebowitz MD. Risk factors associated with complaints of insomnia in a general adult population. Influence of previous complaints of insomnia. Arch Intern Med 1992; 152: 1634-7.

45. Richardson GS, Carskadon MA, Flagg W, Van den HJ, Dement WC, Mitler MM Excessive daytime sleepiness in man: multiple sleep latency measurement in narcoleptic and control subjects. Electroencephalogr Clin Neurophysiol 1978; 45: 621-7.

46. Roehrs T, Zorick F, Wittig R, Conway W, Roth T. Predictors of objective level of daytime sleepiness in patients with sleep-related breathing disorders. Ches 1989; 95: 1202-6.

47. Degaute JP, van de BP, Linkowski P, Van Cauter E. Quantitative analysis of the 24-hour blood pressure and heart rate patterns in young men. Hypertension 1991; 18: 199-210.

48. Degaute JP, van de BP, Kerkhofs M, Dramaix M, Linkowski P. Does non-invasive ambulatory blood pressure monitoring disturb sleep? J Hypertens 1992; 10: 879-85.

49. Davies RJ, Jenkins NE, Stradling JR. Effect of measuring ambulatory blood pressure on sleep and on blood pressure during sleep. Br Med J 1994; 308: 820-3

50. Dimsdale JE, Coy TV, Ancoli-Israel S, Clausen J, Berry CC. The effect of blood pressure cuff inflation on sleep: a polysomnographic examination. Am J Hypertens 1993; 6: 888-91.

51. Heude E, Bourgin P, Feigel P, Escourrou P. Ambulatory monitoring of blood pressure disturbs sleep and raises systolic pressure at night in patients suspected of suffering from sleep-disordered breathing. Clin Sci (Colch) 1996 $91: 45-50$ 